\title{
EMPODERAMENTO POR MEIO DE MULTILETRAMENTOS: UM ESTUDO DE CASO INTERATIVO EM AMBIENTE INFOPOBRE
}

FEMALE EMPOWERMENT THROUGH MULTILITERACIES: A CASE STUDY IN AN ‘INFOPOBRE’ (WITH LACK OF TECHNOLOGY) ENVIRONMENT EMPODERAMIENTO POR MEDIO DE MULTILITERACIDADES: UN ESTUDIO DE CASO INTERACTIVO EN UN ENTORNO ‘INFOPOBRE’ (CON POCA TECNOLOGÍA)

\author{
Layse Henriques da Costa Kitagawa ${ }^{1}$ \\ Bruna Renova Varela Leite ${ }^{2}$ \\ Cláudio Ricardo Corrêa ${ }^{3}$
}

\begin{abstract}
RESUMO
Compreendendo que a tecnologia está inserida em diversos contextos do nosso dia a dia, é muito difícil pensar em práticas do século XXI que não estejam integradas à rede, sobretudo nas grandes cidades. Nesse contexto, o objetivo do trabalho é apresentar atividades em sala de aula com foco em multiletramentos (COPE, KALAZANTZIS, 2000), dado pelo acesso a diversos gêneros textuais em suportes digitais, enfocando o tema do empoderamento feminino. A metodologia adotada foi da pesquisa-ação participante (BRANDÃO, STRECK, 2006), tendo como dispositivo gerador de dados a produção escrita dos estudantes, a fim de propiciar interatividade (SILVA, 2002). Os resultados obtidos demonstram que, ainda que em um ambiente infopobre, apoiados por uma pedagogia multiletrada e multissemiótica, os educandos conseguiram expressar um pensamento crítico acerca do feminismo, e puderam se apropriar de marcas tipográficas oriundas dos meios digitais. Conclui-se que no ensino de línguas adicionais há espaço para participação democrática e crítica dos alunos, que puderam construir conhecimento sobre feminismo, e também para ensino com tecnologias, ainda que as ferramentas sejam escassas.
\end{abstract}

PALAVRAS-CHAVE: Multiletramentos. TICs. Pedagogias. Feminismo.

\section{ABSTRACT}

Understanding that technology is inserted in different contexts of our daily lives, it is very difficult to think of 21 st century practices that are not integrated into the network, especially in large cities. In this context, the objective of this work is to present classroom activities with a focus on multiliteracies (COPE, KALAZANTZIS, 2000), provided by the access to texts of various textual genres on digital media, focusing on the theme of female empowerment. The methodology adopted was of participatory action research (BRANDÃO, STRECK, 2006), bearing as a data generating device the students' written production, in order to provide interactivity

Submetido em: 31/07/2020 - Aceito em: 30/11/2020 - Publicado em: 24/12/2020

\footnotetext{
${ }^{1}$ Mestranda em Letras (Estudo de Línguas - Linguística) pela UERJ.

E-mail: layse_costa@yahoo.com.br. Lattes: http://lattes.cnpq.br/499607659142470

${ }^{2}$ Mestre em Letras (Estudo de Línguas - Linguística) pela UERJ.

E-mail: brunarenova.varela@gmail.com. Lattes: http://lattes.cnpq.br/7677522700175611

${ }^{3}$ Doutorando em Letras (Estudo de Línguas - Linguística) pela UERJ.

E-mail: correadtp@gmail.com. Lattes: http://lattes.cnpq.br/3796199498443886
} 
(SILVA, 2002). The results obtained demonstrate that, even in an infopoor environment, supported by a multiliterate and multisemiotic pedagogy, the students managed to express their critical thought about feminism, and were able to appropriate of typographic marks from digital media. In conclusion, there is room for democratic and critical participation of students in the teaching of additional languages, and also for teaching with technologies, even though the tools were scarce.

KEYWORDS: Multiliteracies. ICTs. Pedagogies. Feminism.

\section{RESUMEN}

Al comprender que la tecnología está insertada en diferentes contextos de nuestra vida cotidiana, resulta difícil pensar en prácticas del siglo XXI que no estén integradas en la red, especialmente en las grandes ciudades. En ese contexto, el objetivo del trabajo es presentar actividades en el aula con enfoque en multiliteracidades (COPE, KALAZANTZIS, 2000), dado por el acceso a diversos géneros textuales en soportes digitales, con énfasis en la temática del empoderamiento femenino. Para ello, se adopta la metodología de investigación-acción participativa (BRANDÃO, STRECK, 2006), cuyo dispositivo generador de datos es la producción escrita de los estudiantes, con el fin de propiciar interactividad (SILVA, 2002). Los resultados obtenidos demuestran que, incluso en un entorno infopobre, apoyado en una pedagogía multialfabetizada y multisemiótica, los estudiantes lograron expresar un pensamiento crítico sobre el femenismo, demostrando capacidad para apropiarse de las marcas tipográficas de los medios digitales. Se concluye que en la enseñanza de idiomas adicionales hay espacio para la participación democrática y crítica de los estudiantes, quienes fueron capaces de construir conocimientos sobre el femenismo, y también para la enseñanza con tecnologías, aunque es en un ambiente con herramientas escasas.

PALABRAS CLAVE Multiliteracidades. TICs. Pedagogías. Feminismo.

\section{INTRODUÇÃO}

Durante as últimas décadas, houve uma ampla inclusão da informática em nossas vidas, especialmente nos principais centros urbanos. Computadores e dispositivos móveis - como tablets e smartphones - tornaram-se economicamente viáveis para parte da população no país e a malha de alcance da Internet de alta velocidade se expandiu. Essa popularização, entretanto, não reflete necessariamente uma real democratização do uso de bens informáticos e suas facilidades, como se vê no Estudo de caso aqui relatado (ver p. 10), desenvolvido numa escola pública no município de Duque de Caxias (RJ). Ainda que não haja uma vasta gama informática disponível em todas as escolas públicas, os alunos não estão alheios aos conteúdos publicados na Internet. Por esse motivo, foi possível realizar um trabalho, que desenvolve o multiletramento, em uma crescente cultura digital, junto a turmas do $6^{\circ}$ ao $9^{\circ}$ ano dessa unidade escolar, com atividade de compreensão auditiva de vídeo em inglês, atividade de compreensão leitora de postagem em redes sociais e expressão escrita, com base nos materiais vistos previamente pelos alunos.

Tendo em vista que grande parte do conteúdo disponível em meios digitais está na forma escrita, assumimos que a questão dos multiletramentos mostra-se importante em trabalhos acadêmicos sobre esse assunto. 
Em termos teóricos, o estudo está apoiado na revisão bibliográfica de diversos textos sobre: a) Multiletramentos (BARBOSA et al, 2016; KAWACHI, 2015; ROJO, 2009, 2012, 2013); b) Gêneros textuais e suporte (DONATO, 2014; LEITE, 2017; LIMA, 2015; MARCUSCHI, 2008; VERGNANO-JUNGER, 2016); c) Feminismo (ADICHIE, 2017, 2018; RIBEIRO, 2018) e d) Tecnologia e interatividade (CARDOSO, 2010; SANTOS, 2016; SILVA, 2002).

\section{PANORAMA SOBRE MULTILETRAMENTOS}

Novos tempos requerem novas estratégias de ensino e aprendizagem. Não que tenhamos que "jogar fora" as antigas, mas precisamos estar abertos às novas estratégias e aos avanços tecnológicos e socioculturais, com o intuito de manter atualizados os modos de ensinar e aprender. Foi pensando nisto que o New London Group ${ }^{4}$ publicou um manifesto intitulado Uma pedagogia dos multiletramentos - desenhando futuros sociais, em 1996, no qual propunha a urgência de a escola assumir ela própria a responsabilidade de criar novas pedagogias que atendessem aos letramentos que surgiam a todo instante nas sociedades contemporâneas.

O que seriam estes multiletramentos? Comecemos pelos letramentos. Para início de conversa, é preciso dizer que letramento não é sinônimo de alfabetização e, portanto, o conceito não deve e não pode ser restringido a alfabetizar (que comumente é entendido como saber codificar e decodificar a escrita). O letramento é maior do que a alfabetização, tendo em vista que envolve engajamento por intermédio de escrita e de leitura, promove interações, estimula o pensamento crítico, reflexões, ações e reações. No letramento, o educando é tratado como sujeito - não um sujeito qualquer, mas protagonista. Enfim, tudo aquilo que Freire (1996) já preconizava: uma educação emancipadora e crítica.

Merece atenção, também, o fato de que o termo é utilizado no plural, já que existem vários tipos de letramentos - uns valorizados e, outros, não. Na língua inglesa isso fica mais claro, pois usa-se literacy para alfabetização e literacies para letramentos. Vários autores, entre eles Cope e Kalantzis (2000, 2013), reconhecem o caráter pluralista do conceito de letramentos e "consideram que o termo no plural revela que as práticas de uso da escrita para ação e atuação em contextos sociais amplos não são singulares: são sempre constituídas por múltiplos elementos" (KAWACHI, 2015, p. 46).

\footnotetext{
${ }^{4}$ Pesquisadores de letramentos, reunidos em 1996, em Nova Londres (Connecticut, EUA), e que após a realização de um colóquio, lançaram um manifesto, no qual apontaram a necessidade de se criar uma pedagogia dos multiletramentos. Entre os que formavam esse grupo, podemos destacar Cazden, C.; Cope, B.; Fairclough, N.; Gee, J.; Kalantzis, M.; Kress, A.; Luke, A.; Luke, C.; Michaels, S. e Nakata, M.
} 
Rojo (2009) considera que os letramentos variam de acordo com os contextos socioculturais (família, igreja, trabalho, escola, mídias sociais...) nos quais estão inseridos e implicam construção social de sentidos por meio da leitura e escrita.

Esses novos letramentos exigem habilidades e competências que não se restringem às linguagens e aos meios educacionais, mas envolvem também interrelações com contextos ideológicos e socioculturais. Justifica-se, assim, o uso do termo multiletramentos como o mais adequado para explicar o impacto desse conjunto de práticas sociais, domínios e usos dos diversos códigos de linguagem e tecnologias (BARBOSA, ARAÚJO e ARAGÃO, 2016).

Segundo Rojo (2012), multiletramentos preveem a necessidade de promoção dos novos letramentos, de caráter multimodal e multissemiótico, que levem as pessoas a aprender a lidar com ferramentas de acesso à comunicação e à informação, e que abranja a multiculturalidade (característica das sociedades globalizadas) e a multimodalidade (dos textos por meio dos quais a multiculturalidade se comunica e informa).

Trabalhar com multiletramentos pode ou não envolver (normalmente envolverá) o uso de novas tecnologias de comunicação e de informação ("novos letramentos"), mas caracteriza-se como um trabalho que parte das culturas de referência do alunado (popular, local, de massa) e de gêneros, mídias e linguagens por eles conhecidos, para buscar um enfoque crítico, pluralista, ético e democrático - que envolva agência - de textos/discursos que ampliem o repertório cultural, na direção de outros letramentos. (ROJO, 2012, p. 8).

Rocha (2010) complementa o conceito acrescentando que, de acordo com Bakhtin, a palavra é ideológica por natureza e nenhum significado é fixo, daí a pedagogia dos multiletramentos destacar o "reconhecimento da diversidade étnica, linguística, identitária e cultural, assim como das múltiplas maneiras de se (re)construir sentidos pelas igualmente diversas formas e meios de comunicação" (ibidem, p. 67).

Isso significa que é preciso ficar atento à facilidade de difusão dos textos em seus diversos gêneros. Mais do que nunca, faz-se necessário promover multiletramentos que permitam uma leitura crítica capaz de reconhecer e reconstruir esses múltiplos sentidos. Para dar conta disso, é preciso que se adotem novas ferramentas e práticas de produção e recepção e, então, a proposta de pedagogias de multiletramentos ganha seu real sentido.

Não se pode mais ficar preso apenas aos letramentos e multiletramentos valorizados, tais como a escola, a escrita jornalística, as modalidades cultas ou restringi-las às verbais. Deixando a inércia de lado, é preciso sair dessa zona de conforto e ultrapassar os limites impostos pelas restrições orçamentárias, pela pobreza, para dar mais sentido às práticas pedagógicas críticas na escola pública. 


\section{GÊNEROS TEXTUAIS E SUPORTE}

A inserção das tecnologias da informação nas sociedades tem acarretado transformações nos seus diversos setores. O usuário de ditas tecnologias precisa se adaptar ao suporte (físico e digital) e conhecer os mecanismos da ferramenta, como uso do mouse, tela tátil, ligar e desligar a máquina, fazer downloads, usar hiperlinks e sites buscadores. Ao usar o suporte, seja ele fixo (como o computador) ou móvel (como o smartphone ou tablet), o usuário tem acesso a diversos gêneros textuais em ambiente digital, sobretudo quando conectado à rede. Por esse motivo, não podemos deixar de mencionar a importância dos gêneros textuais e do suporte para o desenvolvimento do trabalho descrito, neste artigo, na seção Estudo de caso.

Segundo Marcuschi (2008), é impossível estabelecer a comunicação verbal sem algum gênero. Logo, todo ato comunicativo se dá por textos materializados neles.

Usamos a expressão gênero textual (...) para referir os textos materializados que encontramos em nossa vida diária e que apresentam padrões sociocomunicativos característicos definidos por composições funcionais, objetivos enunciativos e estilos concretamente realizados na integração de forças históricas, sociais, institucionais e técnicas. (MARCUSCHI, 2008, p. 155).

Ao aprofundar a noção da linguagem na perspectiva textual-interativa, o autor recusa a concepção de linguagem como um simples suporte para a transmissão de informações e afirma que, além de entendê-la como um "conjunto de símbolos ordenados, ela é vista como uma prática sociointerativa de base cognitiva desenvolvida em contextos comunicativos historicamente situados" (Ibidem, p. 155).

O gênero textual não pode circular na sociedade sem um suporte. Nesse sentido, Marcuschi (2008) aponta que:

\footnotetext{
Entendemos aqui como suporte de um gênero um locus físico ou virtual com formato específico que serve de base ou ambiente de fixação do gênero materializado como texto. Pode-se dizer que suporte de um gênero é uma superfície física em formato específico que suporta, fixa e mostra um texto. (MARCUSCHI, 2008, p.174, grifo nosso).
}

Já Donato (2014) expõe a importância de uma definição de suporte mais substancial que contemple os aspectos presentes no ambiente virtual e no hipertexto.

Assume-se o suporte como um portador de textos escritos e multimodais, responsável não só pela fixação e apresentação dos gêneros materializados, mas também pelo seu transporte e armazenamento. (DONATO, 2014, p. 43).

O suporte digital é constituído de uma parte física e de outra virtual. A nomenclatura suporte digital leva em consideração a evolução do suporte e das tecnologias da informação e 
comunicação (TICs). Com o desenvolvimento do ambiente digital, o avanço tecnológico e o surgimento da Internet não se pode categorizar o desktop ou computador de mesa (suporte fixo) e o tablet e smartphone (suportes móveis) no mesmo bloco que suportes impressos, como o livro. O suporte digital, sobretudo por sua existência relativamente curta na história, tem uma unidade constituinte complexa. Não podemos considerar somente a parte de hardware, que são os dispositivos, nem apenas a parte virtual, que são os aplicativos e sites na web (VERGNANO-JUNGER, 2016; LEITE, 2017).

\section{FEMINISMO}

Não é difícil perceber que as mulheres, em geral, costumam estar em desvantagem em relação aos homens em diversas áreas, restringindo a elas determinados papéis, que não são da mesma maneira impostos aos homens. Na célebre afirmação de Simone de Beauvoir (1980) "não se nasce mulher, torna-se mulher", corrobora-se essa noção de que há uma posição social ideologicamente fabricada para cada gênero.

O 'masculino' e o 'feminino' são criações culturais e, como tal, são comportamentos apreendidos através do processo de socialização que condiciona diferentemente os sexos para cumprirem funções sociais específicas e diversas. Aprendemos a ser homens e mulheres e aceitar como naturais relações de poder entre os sexos. (ALVES; PINTANGUY, 1991, p. 55).

Para superar esse paradigma incutido na práxis social é de extrema importância fazer com que as pessoas consigam enxergar-se imersas nessas estruturas pré-fixadas. Segundo Alves e Pitanguy (1991), tais imposições ideológicas, como a divisão desigual de tarefas domésticas, brincadeiras "naturalmente" separadas para cada sexo são ensinadas desde muito cedo pela família, escola, mídia, religião e devem ser percebidas e combatidas pelos movimentos feministas. É necessário atentar para essas ações corriqueiras, que, na verdade são imbuídas de preconceito:

Ensine a ela que "papéis de gênero" são totalmente absurdos. Nunca lhe diga para fazer ou deixar de fazer alguma coisa "porque você é menina" "Porque você é menina" nunca é razão para nada. Jamais. Lembro que me diziam quando era criança para "varrer direito, como uma menina". O que significava que varrer tinha a ver com ser mulher. Eu preferiria que tivessem dito apenas para "varrer direito, pois assim vai limpar melhor o chão". E preferiria que tivessem dito a mesma coisa para os meus irmãos. (ADICHIE, 2017, p. 21).

Esse conjunto de costumes deve ser combatido, pois, numa análise mais aprofundada, proposta por Beauvoir (1980), o demérito da mulher em relação ao homem, leva a um sufocamento da busca intrínseca do ser humano em realizar-se, transcender, para uma existência voltada para um viver em função do outro. Essas renúncias, na verdade, legitimam 
uma "violência suave, insensível, invisível a suas próprias vítimas, que se exerce essencialmente pelas vias puramente simbólicas da comunicação [...] ou, em última instância, do sentimento" (BOURDIEU, 2012). Combater essa violência, presente no campo das relações sociais mediadas pelo discurso e muitas vezes observada nas interações em redes sociais, é extremamente necessário.

Na obra Quem tem medo do feminismo negro? (RIBEIRO, 2018) é levantada a questão do racismo associada ao machismo instituído na cultura brasileira. A autora pontua a necessidade de que as lutas feministas trabalhem na busca de ganhos para a coletividade, não apenas para grupos privilegiados, como nos primórdios do feminismo, em que foram ignoradas as categorias de mulheres racializadas, periféricas, fazendo parte de diversas minorias.

Segundo a autora, o empoderamento feminino é mais profundo que uma troca de poder dos homens para as mulheres, ou uma luta a ser travada por cada mulher individualmente, mas "[t]rata-se de empoderar a si e aos outros e colocar as mulheres como sujeitos ativos da mudança (...). É perceber que uma conquista individual não pode estar descolada da análise política." (ibidem). Nesse sentido, as mulheres devem deixar de esperar que sejam apenas beneficiárias de políticas públicas, mas passar a idealizá-las, num clamor por maior participação em esferas públicas.

Uma grande conquista na esfera Legislativa brasileira foi a lei № 11.340 no ano de 2006, a Lei Maria da Penha, apesar de ter sido necessário que o Brasil fosse condenado pela Comissão Interamericana de Direitos Humanos em 2001 pela omissão de resposta jurídica à vítima. A partir de sua sanção, foram encarados como possível sujeito ativo contra a mulher não apenas o cônjuge, mas homens de seu convívio e compreende como delitos não apenas a violência física, mas outras formas de agressão psicológica e moral:

Art. $7^{\circ}$ São formas de violência doméstica e familiar contra a mulher, entre outras:(...)

II - a violência psicológica, entendida como qualquer conduta que lhe cause dano emocional e diminuição da autoestima ou que lhe prejudique e perturbe o pleno desenvolvimento ou que vise degradar ou controlar suas ações, comportamentos, crenças e decisões, mediante ameaça, constrangimento, humilhação, manipulação, isolamento, vigilância constante, perseguição contumaz, insulto, chantagem, violação de sua intimidade, ridicularização, exploração e limitação do direito de ir e vir ou qualquer outro meio que lhe cause prejuízo à saúde psicológica e à autodeterminação; [...]

$\mathrm{V}$ - a violência moral, entendida como qualquer conduta que configure calúnia, difamação ou injúria. (BRASIL, 2006).

Por conter uma visão interseccional de feminismo negro e não europeu ou norte-americano, as obras Sejamos todos feministas e Para educar crianças feministas - um manifesto, ambos de Chimamanda Ngozi Adichie (2015, 2017), escritora nigeriana, foram leituras preliminares que motivaram este trabalho. Por conter uma linguagem acessível e empenho em trazer à luz 
questões do cotidiano sob uma perspectiva feminista, foi percebida uma oportunidade de tocar no assunto com uma leitura mais próxima do que os discentes fazem em seu tempo livre, diferindo-se, assim, dos textos geralmente encontrados nos livros didáticos utilizados na escola.

Foram utilizados pelos alunos envolvidos nesta pesquisa, em língua inglesa, além de excertos de textos impressos e partes de entrevistas dadas pela autora Chimamanda Ngozi Adichie em programas de TV, e também textos autênticos de outros autores, de sites e jornais internacionais. Foi incluída uma reportagem a respeito de Marielle Franco, parlamentar feminista ativamente engajada em diversas lutas por direitos humanos, vinda de um contexto urbano proletário do Rio de Janeiro, que muito lembra a realidade dos alunos da periferia de Duque de Caxias, baixada fluminense. A vereadora assassinada foi lembrada neste projeto, com o intuito de que sua memória seja respeitada e valorizada.

\section{TECNOLOGIA E INTERATIVIDADE}

Nas décadas de 70 e 80, florescia uma nova tecnologia computacional. O que anteriormente era complexo e técnico evoluiu para uma forma mais acessível e intuitiva de se lidar com a informática pelo advento das janelas, depois o mouse e em seguida, os celulares com acesso à Internet $\mathrm{e}$ às redes sociais.

Como sucessora da Web 1.0, que permitia apenas acesso a informações sem oportunidades de interação, a Web 2.0 trouxe valiosas possibilidades no campo das relações humanas e ensino/aprendizagem ao permitir que os usuários colaborem com os conteúdos apresentados em diversos formatos. As redes sociais, wikis, blogues e outros sites que permitem upload de textos, imagens e vídeos são alguns exemplos dessa nova modalidade de Internet.

Há uma vasta gama de opções de autodesenvolvimento para docentes e discentes, permitindo otimização de criatividade, relacionamento com pessoas de outros locais do mundo, oportunizando uma prática autêntica do idioma lecionado e desenvolvendo autonomia (CARDOSO, 2010). Utilizar a Web 2.0 é uma boa oportunidade de levar o ensino/aprendizagem de inglês para fora da escola.

Esse conjunto trouxe à tona a interatividade (SILVA, 2002), que iria delinear no passar dos anos uma nova forma de agir socialmente. Para entender os níveis de interatividade, é interessante seguir a gradação proposta por Kretz (1985 apud SILVA, 2002). No Grau Zero de Interatividade, encontram-se os meios de comunicação de massa em que o sujeito exerce um papel de receptor absolutamente passivo, cabendo a ele a escolha de acessar ou não esta ou aquela informação. Em seguida, a Interatividade Linear no qual a informação está 
disponível como uma obra completa que pode ser manipulada no que diz respeito à ordem, como no folhear de um livro. A Interatividade Arborescente oferece ao leitor um menu, possibilitando que faça escolhas, como numa revista. Já na Interatividade Linguística, as escolhas são feitas através de palavras-chave ou formulários. O próximo nível, a Interatividade de Criação, permite a elaboração de mensagens de variadas formas: textual, gráfica, sonora e outras. A última, Interatividade de Comando Contínuo, permite a manipulação de elementos, como nos videogames.

Segundo Silva (2002), essa evolução da tecnologia mudou parâmetros da sociedade, antes familiarizada com uma interatividade de grau zero, receptora de informações, estava de acordo com um estilo de ensino sem espaço para interação ou autoria dos alunos. Este modelo, porém, perdeu espaço a partir do acesso à Internet e à Web 2.0, democratizada atualmente, urgindo para a necessidade de uma mudança de postura do professor, que deve buscar fornecer condições para que sua sala de aula seja interativa:

ambiente em que o professor interrompe a tradição do falar/ditar, deixando de identificar-se com o contador de histórias, e adota uma postura semelhante à do designer de software interativo. Ele constrói um conjunto de territórios a serem explorados pelos alunos e disponibiliza co-autoria e múltiplas conexões, permitindo que o aluno também faça por si mesmo. (SILVA, 2002, p. 23).

Essa visão de sala de aula combina com o perfil não só de aluno, mas de indivíduo da atualidade, que tem suas relações interpessoais e seu aprender profundamente transformados e potencializados, extrapolando as barreiras do mundo físico:

A noção de espaço de aprendizagem vai além dos limites do conceito de espaço/lugar. Com a emergência da 'sociedade em rede', novos espaços digitais e virtuais de aprendizagem vêm se estabelecendo a partir do acesso e do uso criativo das novas tecnologias da comunicação e da informação. Novas relações com o saber vão-se instituindo num processo híbrido entre o homem e a máquina, tecendo teias complexas de relacionamentos com o mundo. (SANTOS, 2016, p. 55).

Lamentavelmente, a referida interatividade e hibridação entre educadores, educandos e tecnologias não é uma realidade possível para muitos alunos e escolas. Os locais ou indivíduos que não dispõe de computadores, celulares, Internet, que estão alheios a todas essas possibilidades de interação, são denominados 'infopobres' (SILVA, 2002), categoria em que estão inseridos boa parte dos discentes participantes desta pesquisa.

Não se pode deixar de destacar, também, o papel político que as mídias carregam, principalmente as redes sociais, que têm sido fortemente usadas para esse fim no presente. É necessário buscar desenvolver nos discentes um nível de compreensão que permita-os ser avaliadores e não apenas consumidores daquilo a que são expostos. Com esse pensamento, neste trabalho nos esforçamos para buscar pôr em prática uma educação orientada para a 


\section{Revista Docência e Cibercultura}

participação democrática e questionamento das ideias compartilhadas nos ambientes virtuais (ROCHA; MACIEL, 2015).

Neste ponto, entrelaçam-se Web2.0, interatividade, multiletramentos, gêneros textuais diversos, feminismo, pois a rede social é o espaço onde são expostas manifestações das mais variadas. O importante é valorizar a cidadania e respeito num fazer orientado para a "participação social, dentro e fora da escola, como um processo mais humanizador, colaborativo e não-hierarquizado" (idem, p. 23).

\section{ESTUDO DE CASO}

O trabalho aqui descrito ocorreu durante as aulas de língua inglesa em turmas do sexto ao nono ano, numa escola municipal situada em Duque de Caxias. Devido a relatos e vivências no ambiente escolar, foi percebida a necessidade de abordar o assunto do feminismo, pois alunos e alunas reproduziam um discurso de aceitação e naturalização da violência contra a mulher. Além disso, algumas alunas muito jovens optavam pela vida marital em lugar da escolarização, abandonando os estudos ainda no segundo segmento do nível fundamental. Para lidar com essa realidade, foi desenvolvido um trabalho voltado para os multiletramentos (ROJO, 2012), com todos os textos de apoio provenientes de sites na Internet. Parte da pesquisa proposta para os alunos se deu nas redes sociais, como será descrito a seguir.

Por tratar-se de uma pesquisa-ação participante (BRANDÃO, STRECK, 2006), os sujeitos envolvidos não foram meramente observados, mas construíram e conduziram o estudo junto à pesquisadora, professora de língua inglesa na escola já citada. Os nomes dos alunos foram suprimidos para preservação da identidade.

A ideia inicial era de utilizar tecnologia, aparelhos celulares em sala para executar as atividades, dando voz aos educandos nas redes, para que fosse desenvolvido um ambiente favorável à criação de conhecimento em conjunto, a interatividade (SILVA, 2002). Tal intento não foi alcançado, uma vez que a maioria dos alunos não dispunha de celulares ou Internet móvel, tampouco a escola da rede em questão oferece ferramentas digitais para uso de alunos e professores, o que caracteriza um ambiente 'infopobre' (SILVA, 2002). Logo, os textos multimodais tiveram de ser impressos e as manifestações pessoais foram escritas à mão.

Inicialmente, foram apresentados textos multimodais autênticos, retirados de sites com um pequeno resumo de cada um dos quinze capítulos do livro Como educar crianças feministas 
da autora nigeriana Chimamanda Ngozi Adichie, além de uma sequência de vídeos intitulados como "Chimamanda responde" disponíveis no canal de Youtube Marie Claire Brasil, ${ }^{5}$ em que a autora respondia a comentários contra o empoderamento feminino lidos em postagens do Instagram. O objetivo dessa etapa era conceituar feminismo pelo ponto de vista da autora, desmistificando o senso comum sobre o assunto. A leitura do trecho em inglês foi feita em pequenos grupos, com auxílio de dicionários ou pesquisa em sites de busca, além do auxílio da professora, circulando pela sala de aula para sanar dúvidas.

Na Figura 1, encontra-se uma dessas páginas utilizadas em aula, com trecho impresso e espaço para manifestações pessoais dos alunos. Eles tiveram liberdade de expressarem as opiniões individualmente ou em pequenos grupos.

\section{Gender roles}

A child should not be taught that they should or should not do something because of their gender.. Conditioned gender roles such as the pink vs blue and toy differentiation are difficult to unlearn therefore it is important that children reject them from the beginning.

I um dia minha sirmã fai faga balimha de gude ai a Nisinha chama lla de Pira par que ela tarra faganda na mia das meninas se pais minha fol mă mãa dejrsar ela faga mais)

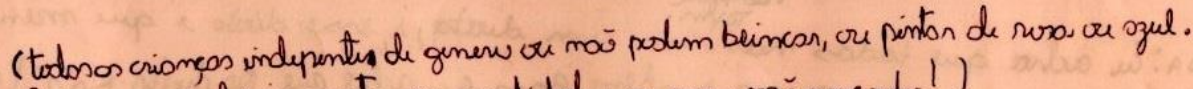

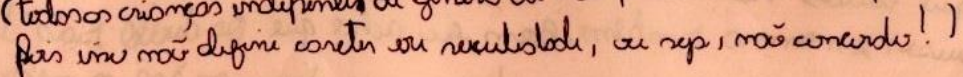

\section{1}

\section{1}

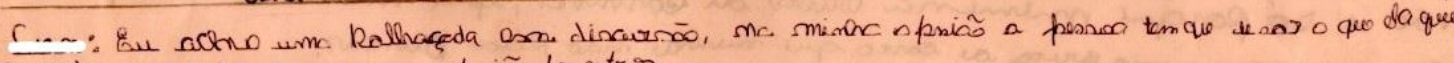
Sam tam que se prescupar con a cohnicĩo dos outros.

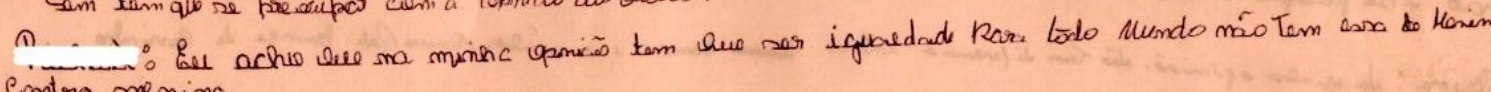
Contre menima

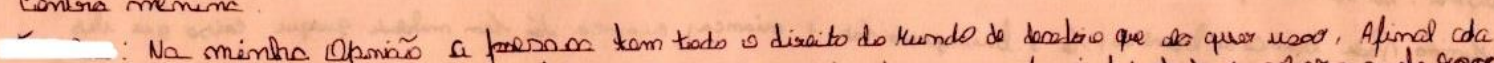

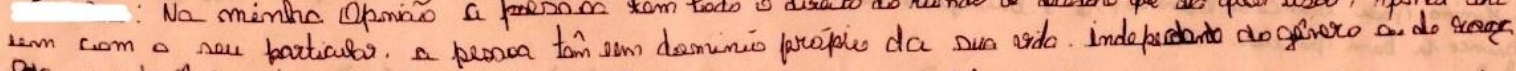

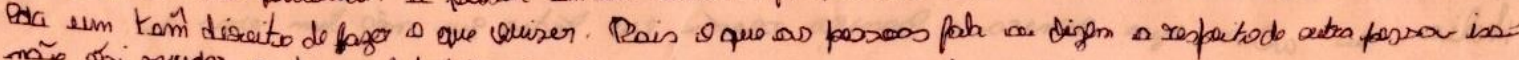
mis chi mudes a personalidad de ainguém
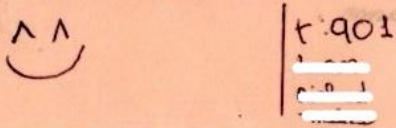

Figura 1. Trecho de texto retirado da Internet e opiniões dos discentes.

Fonte: Alunos

Após essa etapa, os alunos se juntaram em duplas ou trios para pesquisar feministas no Brasil e no mundo e apresentar aos colegas informações a respeito dessas pessoas. Eles fizeram

\footnotetext{
${ }^{5}$ Disponível em: https://www.youtube.com/watch?v=728Arry6g7o\&t=6s.
} 


\section{Revista Docência e Cibercultura}

minicartazes com imagens e informações. Houve uma predominância de personagens históricas femininas, como Joana D'arc, Marie Curie, porém mulheres e homens da atualidade também foram lembrados, como Beyoncé, Angela Davis, Joseph Gordon, entre outros, além de uma personagem fictícia, Nairóbi da série “A casa de papel”, que instaurou o matriarcado em um episódio da trama.

Em seguida, a professora apresentou slides com propagandas, postagens de redes sociais, músicas nacionais e internacionais que carregavam um discurso machista, para que os alunos opinassem e discorressem a respeito. Cada slide fora projetado com auxílio de projetor (o único da escola) e, em sequência, disponibilizados individualmente em folhas com espaço para opiniões. Os alunos tiveram liberdade de escolher quais textos gostariam de comentar. Nesse momento, foi bastante interessante perceber a mistura de gêneros textuais nas manifestações dos alunos. Como os textos foram em sua totalidade retirados da Internet, os alunos utilizaram caracteres, expressões típicas desse suporte, como exemplificado nas imagens da Figura 2.
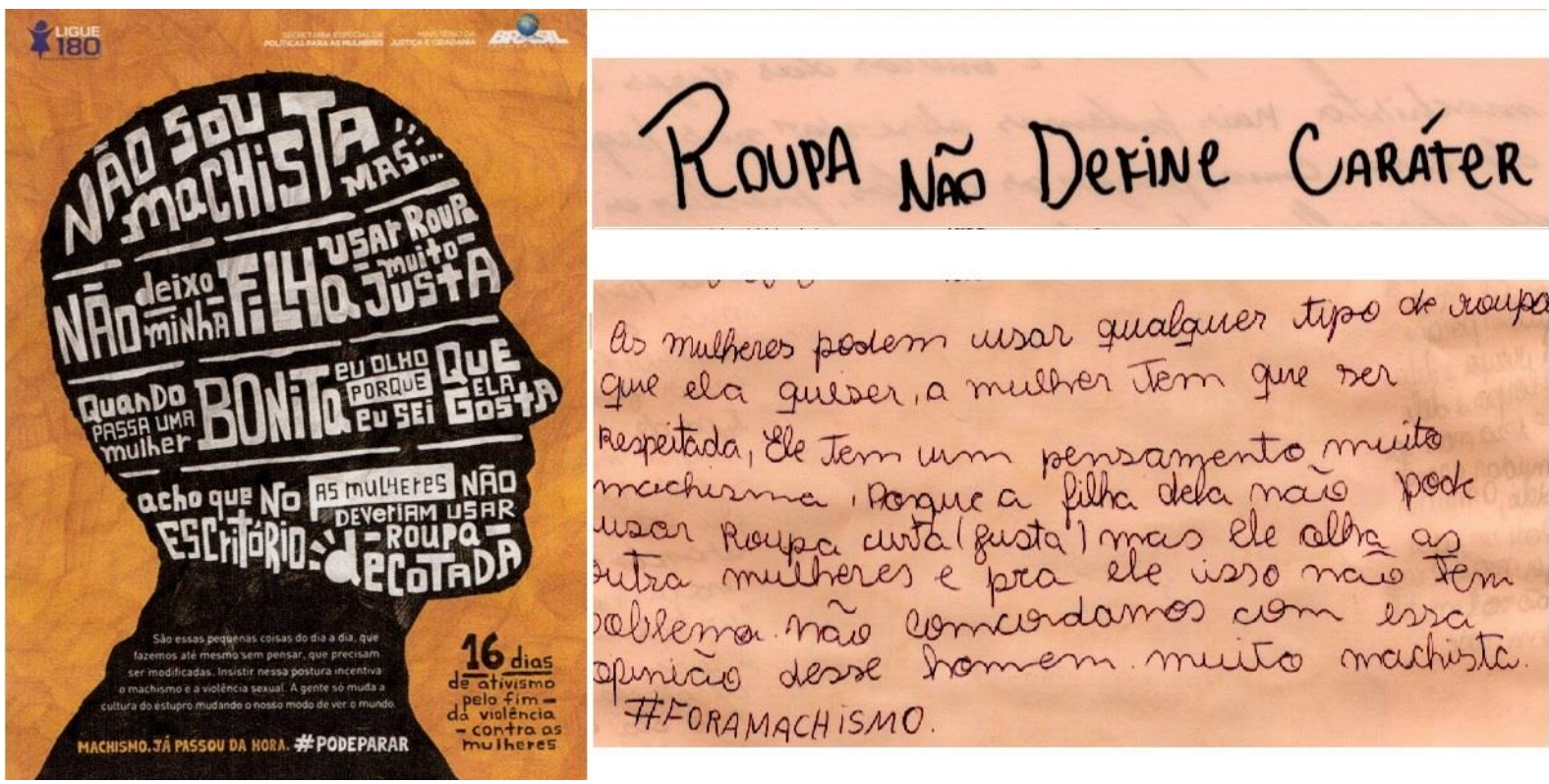

Figura 2. À esquerda, texto multimodal apresentado pela professora, à direita duas manifestações de alunos.

Fonte: Alunos

O uso de letras maiúsculas na Internet caracteriza uma ênfase ou grito. Na mensagem passada pelo aluno: "ROUPA NÃO DEFINE CARÁTER", há uma semelhança com palavras de ordem usadas em um protesto, que no caso é feito contra a visão de mundo machista apresentada na campanha. Ao final da frase seguinte, foi utilizada uma hashtag: 
\#FORAMACHISMO, típico dos ambientes virtuais. Tal linguagem híbrida, na medida em que incorpora elementos das redes sociais num escrito em papel, é indício de que esses letramentos digitais foram alcançados para sujeitos inseridos na unidade escolar, mesmo em um ambiente infopobre, sem estímulos ou acesso à tecnologia para todos.

Em seguida, os alunos deveriam buscar por publicações que também apresentassem traços de misoginia e encaminhá-los à professora via Whatsapp, já com uma pequena descrição problematizando o texto encontrado para que em seguida seus colegas opinassem. Pela inviabilidade de alguns alunos desempenharem essa tarefa por falta de recursos tecnológicos em casa, foi combinado que em cada grupo pelo menos um aluno tivesse acesso às redes para que fosse possível ter uma experiência com a tecnologia.

A Figura 3 foi retirada de comentários de um grupo para gamers encontrado numa rede social. A postagem é a respeito de um vídeo feito por uma garota e os comentários refletem o menosprezo dessa comunidade, predominantemente composta por membros do sexo masculino, à participação dessa menina, que, segundo eles, deveria estar se dedicando a outras atividades.

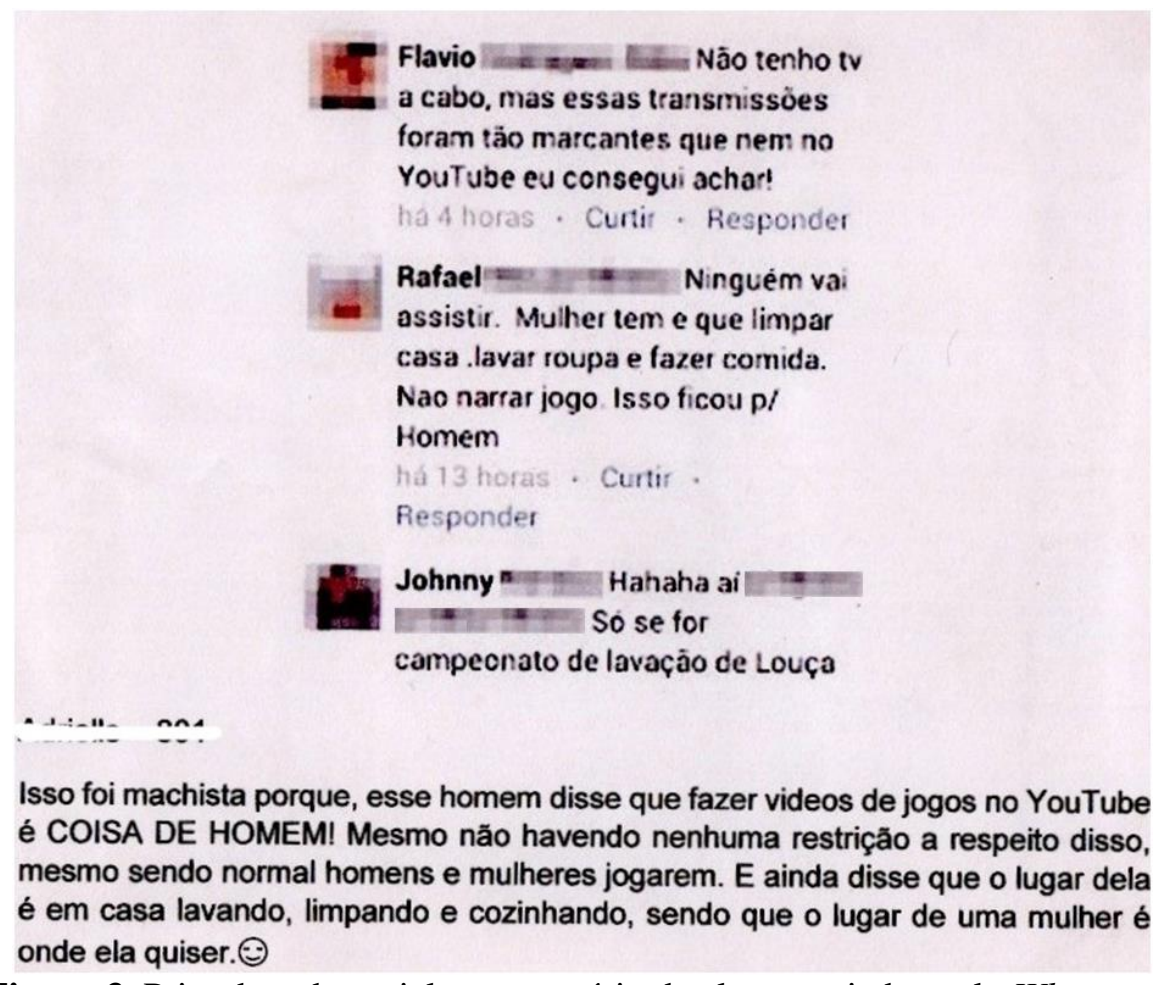

Figura 3. Print de rede social e comentário de aluna enviados pelo Whatsapp. Fonte: Alunos 
Percebe-se que a aluna que encontrou essa postagem e redigiu suas impressões pessoais, é bem familiarizada com a linguagem utilizada nesse suporte virtual, uma vez que mencionou site, utilizou emoticon, letras maiúsculas para enfatizar sua revolta contra a fala machista verificada nos comentários que ela encontrou. Por sua manifestação pessoal, foi possível perceber o quão importante é dar espaço e estimular que a leitura crítica seja feita no dia a dia de cada aluno, para que se possa criar uma sociedade em que todos tenham direito de se posicionar e não aceitar passivamente discursos que minimizem ou marginalizem sujeitos.

É de suma importância que seja oferecido espaço para esse tipo de discussão e estimular que o alunado tenha seu posicionamento, em diversos níveis de escolarização, principalmente na educação básica:

a educação linguística plurilinguisticamente orientada e voltada para a participação democrática, não pode mais desconsiderar questões de poder, ou contextos sócio-históricos de produção de culturas e discursos, incluindo-se os midiáticos. Por esse prisma, os letramentos digitais podem ser vistos, grosso modo, como modos de pensarmos e dizermos o mundo pelas lentes das novas tecnologias e mídias, simultaneamente questionando-as e transformando-as. (ROCHA; MACIEL, 2015, p. 25).

Essa participação democrática citada pelos autores é de grande valia, principalmente na sociedade atual, pois se a escola e os educadores não criarem espaços seguros para questionamentos, não serão governos ou mídias a dar espaço para a transformação desejada.

\section{CONSIDERAÇÕES FINAIS}

A partir das demonstrações de opiniões dos alunos envolvidos no estudo de caso, é possível perceber que as salas de aula de língua estrangeira oferecem espaço fértil para discussão sobre questões sociais e busca de direitos a partir dos multiletramentos e da interatividade. Foi possível, além de estimular a discussão, conhecer os pontos de vista, e então, empoderar os discentes, colocando-os numa posição ativa na criação de conhecimento. É tarefa dos educadores permitir que salas de aula sejam espaços de exercer cidadania e propor mudanças de comportamento, criticando posturas que diminuam sujeitos nas práticas sociais.

Percebemos, de igual maneira, que, apesar de carecer de oferta de tecnologia, a escola é um ambiente que pode propiciar o trabalho com uso das TICs. Por meio do processo leitor e acesso a vídeos, a professora conseguiu propor atividades que levam em consideração o multiletramento: i) os discentes demonstraram familiaridade com os gêneros textuais acessados (mesmo no caso da postagem/comentário, típicos do ambiente digital, ${ }^{6}$ uma aluna

\footnotetext{
${ }^{6}$ Concordando com Lima (2015), ressaltamos que post/comentário são gêneros textuais tipicamente digitais. O comentário mantém uma relação de dependência com o post, pois sem esse gênero, aquele não existe.
} 
identificou elementos típicos desses gêneros e os reproduziu em texto de produção própria por um aplicativo de mensagem instantânea); ii) mostraram ser capazes de fazer buscas pelos suportes fixo (computador) e móvel (smartphone); iii) demostraram proficiência em contato com o constituinte virtual do suporte, ao acessarem sites, hiperlinks, redes sociais e aplicativos de mensagem instantânea.

A carência de estrutura, entrave encontrado na realização desta pesquisa, traz à tona a realidade de muitas unidades escolares. As escolas poderiam ser espaços de democratização do uso de ferramentas digitais para os menos favorecidos, mas muitas falham nessa tarefa tão importante, pois não são raras as exigências da atualidade para que os indivíduos utilizem tecnologias em seu cotidiano.

As pedagogias de multiletramentos estão sendo criadas e implementadas mais por iniciativas isoladas do que por políticas públicas. Aproveitamos a experiência relatada no estudo de caso para questionar a viabilidade de um ensino a distância - sem planejamento prévio e feito às pressas - como o proposto pela secretaria de educação do estado do Rio de Janeiro, em 2020, diante da pandemia da Covid-19. Como serão incluídos os indivíduos carentes? Sem conhecer ou se importar com a realidade daqueles que não terão acesso às ferramentas necessárias, parece muito pouco acenar com materiais impressos a serem distribuídos. Que materiais são esses (sejam digitais ou analógicos)? Elaborados por quem?

Diante das questões levantadas, experiências relatadas e leituras expostas neste artigo, chamamos a atenção para o poder transformador dos multiletramentos e para como a educação, quando comprometida com a participação democrática, deve atentar para os meios externos à escola, incluindo-se a participação nos ambientes digitais, intrínsecos ao cotidiano de boa parte (mas, não da totalidade) dos discentes da atualidade. Manter neutralidade, mediante questões que perpassam e tencionam as relações humanas, é abster-se de uma responsabilidade social tão cara em tempos de busca de cerceamento da liberdade de cátedra e direitos dos educadores. 


\section{REFERÊNCIAS}

ADICHIE, Chimamanda Ngozi. Para educar crianças feministas: um manifesto. São Paulo: Companhia das Letras, 2017.

ALVES, Branca Moreira; PITANGUY, Jacqueline. O que é feminismo. Abril Cultural: Brasiliense, $8^{a}$ ed. São Paulo, 1991.

BARBOSA, Vânia Soares; ARAÚJO, Antonia Dilamar; ARAGÃO, Cleudene de Oliveira. "Multimodalidade e multiletramentos: análise de atividades de leitura em meio digital".

RBLA, Belo Horizonte, v. 16, n. 4, p. 623-650, 2016.

BEAUVOIR, Simone. O Segundo Sexo, v. I, II. Tradução Sérgio Milliet. Rio de Janeiro: Nova Fronteira, 1980 apud SANTOS, Magda Guadalupe. Disponível em http://periodicos.pucminas.br/index.php/SapereAude/article/viewFile/2081/2250. Acesso em 27 jul. 2020.

BOURDIEU, Pierre. A dominação masculina. Tradução de Maria Helena Kühner. $11^{\mathrm{a}}$ ed. Rio de Janeiro: Bertrand Brasil, 2012 apud FERREIRA JÚNIOR, Agnaldo Paulino. Disponível em:

http://periodicos.pucminas.br/index.php/SapereAude/article/viewFile/17469/13413. Acesso em 25 jul. 2020.

BRANDÃO, Carlos Rodrigues; STRECK, Danilo Romeu. (Orgs). Pesquisa participante: a partilha do saber. Aparecida - SP: Ideias \& Letras, 2006.

BRASIL. Lei $\mathbf{n}^{\mathbf{0}}$ 11.340, de 07 de agosto de 2006. Brasília, DF, Disponível em: http://www.planalto.gov.br/ccivil_03/_Ato2004-2006/2006/Lei/L11340.htm. Acesso em: 07 mar. 2019.

CARDOSO, Janaina da Silva. Tecnologia como uma ferramenta poderosa no aprendizado de idiomas. In: POSSAS, Sandra. (Org.). Inglês na sala de aula: ação e reflexão. São Paulo: Moderna/Richmond, 2010.

COMISSÃO INTERAMERICANA DE DIREITOS HUMANOS, Caso 12.051, Relatório 54/01, Maria da Penha Maia Fernandes $v$. Brasil, 2001. Disponível em: http://www.sbdp.org.br/arquivos/material/299_Relat\%20n.pdf. Acesso em 27 jun. 2020.

COPE, Bill; KALANTZIS, Mary. (Eds.). Multiliteracies: Literacy Learning and the Design of Social Futures. London: Routledge, p. 121-234, 2000.

COPE, Bill; KALANTZIS, Mary. (Eds.). Multiliteracies: New Literacies, New Learning. In: HAWKINS, M. R. (Org.). Framing Languages and Literacies: Socially Situated Views and Perspectives, New York: Routledge, p. 105-135, 2013. 
DONATO, Aline de Bettencourt. Gêneros textuais introdutórios e suporte: uma visão sociocognitiva da revista Nova Escola. 2014. 154 f. Dissertação (Mestrado em Línguística Instituto de Letras, Universidade do Estado do Rio de Janeiro, Rio de Janeiro, 2017.

FREIRE, Paulo. Pedagogia da autonomia: saberes necessários à prática educativa. São Paulo: Paz e Terra, 1996.

KAWACHI, Guilherme Jotto. "Entre letramentos e multiletramentos: contribuições teóricas para um ensino crítico de língua inglesa". Dossiê Especial: Formação Docente, Tecnologias Digitais e Educação Crítica. ROCHA, Claudia Hilsdorf; HIBARINO. Denise; AZZARI, Eliane Fernandes (orgs.) Revista X, vol. 2, 2015.

KRETZ, Francis. Le concept pluriel d'interactivités ou l'interactivité vous laisse-t-elle chaud ou froid. In: Bulletin de l'IDATE. Paris: Centro Georges Pompidou, nº 20, julho de 1985.

LEITE, Bruna Renova Varela. Caracterizando suporte digital e gêneros textuais em dispositivos fixo e móvel. 2017.172 f. Dissertação (Mestrado em Línguística). Instituto de Letras, Universidade do Estado do Rio de Janeiro, Rio de Janeiro, 2017.

LIMA, Raquel Freitas de. O par post/comentário em rede social: um estudo a partir da noção de gêneros textuais. 2015. 183 f. Dissertação (Mestrado em Linguística). Instituto de Letras, Universidade do Estado do Rio de Janeiro, Rio de Janeiro, 2015.

MARCUSCHI, Luiz Antônio. Produção textual, análise de gêneros e compreensão. São Paulo: Parábola, 2008.

RIBEIRO, Djamila. Quem tem medo do feminismo negro? São Paulo: Companhia das Letras, 2018.

ROCHA, Claudia Hilsdorf. Propostas para o inglês no ensino fundamental I público: plurilinguismo, transculturalidade e multiletramentos. Tese (Doutorado em Linguística Aplicada), Universidade Estadual de Campinas, Instituto de Estudos da Linguagem. Unicamp, Campinas, SP, 2010.

ROCHA, Claudia Hilsdorf; MACIEL, Ruberval Franco. (Orgs). Língua estrangeira e formação cidadã: por entre discursos e práticas. Campinas: Pontes, 2015.

ROJO, Roxane. Letramentos Múltiplos: escola e inclusão social. São Paulo: Parábola Editorial, 2009.

ROJO, Roxane; MOURA, Eduardo. (Orgs.) Multileramentos na escola. São Paulo: Parábola Editorial, 2012.

ROJO, Roxane. (Org.) Escol@ conectad@: os multiletramentos e as TICs. São Paulo: Parábola Editorial, 2013. 
SANTOS, Edméa (Org.). Mídias e tecnologias na educação presencial e a distância. Rio de Janeiro: LTC, 2016.

SILVA, Marco. Sala de Aula Interativa. $3^{\text {a }}$ ed. Rio de Janeiro: Quartet, 2002.

VERGNANO-JUNGER, Cristina de Souza. Uma leitura puxa outra: o potencial da hipertextualidade digital no desenvolvimento da compreensão leitora em espanhol como língua estrangeira. III CIPLOM, Florianópolis, 2016. NC- 4.0), que permite uso, distribuição e reprodução para fins não comerciais, com a citação dos autores e da fonte original e sob a mesma licença. 